\title{
Clinico-Demographic Characteristics of Intestinal Tuberculosis in Pre-Operative Unsuspected Laparotomy as Incidental Findings in Bangladesh
}

\author{
Md. Mizanur Rahman', Ayub Ali'2, Md. Abdullah Yusuf3, Md. Zamil Zaidur Rahim", \\ Md. Mahfuzur Rahman', Zahir-ul Islam6 \\ ${ }^{1}$ Gafargaon Upazilla Health Complex, Mymensingh, Bangladesh \\ ${ }^{2}$ Shadar General Hospital, Cox's Bazar, Bangladesh \\ ${ }^{3}$ Department of Microbiology, National Institute of Neurosciences \& Hospital, Dhaka, Bangladesh \\ ${ }^{4}$ Department of Orthopedics, Combined Military Hospital, Comilla, Bangladesh \\ ${ }^{5}$ Department of Neurosurgery, National Institute of Neurosciences \& Hospital, Dhaka, Bangladesh \\ ${ }^{6}$ Railway General Hospital, Dhaka, Bangladesh \\ Email: mizan2121@yahoo.com, drayubortho@gmail.com, ayusuf75@yahoo.com,zamil1969@yahoo.com, \\ dr.mahfuz.ns76@gmail.com,drzahir.ortho@gmail.com
}

How to cite this paper: Rahman, M.M., Ali, A., Yusuf, M.A., Rahim, M.Z.Z., Rahman, M.M. and Islam, Z. (2017) Clinico-Demographic Characteristics of Intestinal Tuberculosis in Pre-Operative Unsuspected Laparotomy as Incidental Findings in Bangladesh. Journal of Tuberculosis Research, 5, 139-145. https://doi.org/10.4236/jtr.2017.52015

Received: April 15, 2017

Accepted: June 20, 2017

Published: June 26, 2017

Copyright $\odot 2017$ by authors and Scientific Research Publishing Inc. This work is licensed under the Creative Commons Attribution-NonCommercial International License (CC BY-NC 4.0). http://creativecommons.org/licenses/by-nc/4.0/ (c) (i) (8) Open Access

\begin{abstract}
Background: Clinical presentation of intestinal tuberculosis is varied. It is also essential to know the clinical and demographic characteristics of incidentally detected intestinal tuberculosis patient. Objective: The purpose of the present study was to find out the clinic-demographic characteristics of intestinal tuberculosis in clinically and preoperatively unsuspected laparotomies. Methodology: This cross-sectional study was carried out in the Department of Surgery at Dhaka Medical College Hospital, Dhaka from March 2002 to March 2004 for a period of two (2) years. All the patients underwent laparotomy presented without any suspicion of pulmonary or intestinal tuberculosis were included as study population. Patients who were without the history of cough, haemoptysis, antitubercular drug therapy were included. Per operative suspicion was raised due to enlarged lymph nodes in mesentery, omental masses, ileocaecal masses, suspicious growth in ileum, omental thickening, perforation suspected by tuberculosis. Biopsy was taken from suspicious lesions. Histopathology was confirmed the tubercular lesion. Results: A total number of 300 patients under laparotomy were recruited for this study of which 38 positive cases were found in the study with a percentage of $12.7 \%$. Maximum affected age group was 21 to 30 years which was 16 (42\%) cases. Male was predominant to female which was 28 (73.7\%) cases and $10(26.3 \%)$ cases respectively. Low socioeconomic people are affected more (76.3\%). Most
\end{abstract}


common presentation in positive cases was acute and sub-acute intestinal obstruction 20 (52.6\%) followed by intestinal perforation (26.31\%). Conclusion: In conclusion young age male patient is the most commonly affected intestinal tuberculosis which is frequently presented with sub-acute intestinal obstruction among the preoperatively unsuspected laparotomy patients.

\section{Keywords}

Intestinal Tuberculosis, Unsuspected, Laparotomy, Clinic-Demographic Characteristics

\section{Introduction}

Intestinal tuberculosis is organ and peritoneum specific [1]. However, the organ-involving tuberculosis is divided into hypertrophic and ulcerative; again the peritoneal tuberculosis is classified into ascitic, encysted, fibrous and purulent types [2]. Hypertrophic type affects predominantly ileocaecal region. This is characterized by absence of gross caseation with marked thickening of sub mucous and subserosal layer. On the other hand ulcerative type affects predominantly terminal ileum where multiple deep transverse ulcers develop and extent to serosa which may give rise to perforation [3].

Although majority of cases report with constitutional features along with altered bowel habit, abdominal pain and sub acute intestinal obstruction, however, sometimes patients present very lately with an acute abdomen as well as complete intestinal obstruction [4]. These variations of clinical features give a diagnostic dilemma. Furthermore the clinical features of intestinal tuberculosis are mimicking with other intestinal diseases [5]. Therefore this present study was undertaken to find out the clinical and demographic characteristics of preoperatively unsuspected intestinal tuberculosis patients with preoperatively.

\section{Methodology}

This cross-sectional study was conducted in different units of the Department of Surgery at Dhaka Medical College Hospital, Dhaka from March 2002 to March 2004 for a period of two (2) years. All the patients underwent laparotomy presented without any suspicion of pulmonary or intestinal tuberculosis were included as study population. Purposive sampling method was performed during enrollment of the patients after considering the inclusion and exclusion criteria. Patients with no suspicion about pulmonary as well as intestinal tuberculosis, no history of cough and haemoptysis, no previous history of antitubercular drug or diagnosed as other than tuberculosis were selected as study population. Patients with known case of tuberculosis, suspicion about pulmonary tuberculosis, history of cough \& haemoptysis, previously treated with antitubercular drugs and chest X-ray with suspicion of pulmonary tuberculosis were excluded from this study. Per operative suspicion about intestinal tuberculosis was raised by ob- 
serving the enlarge lymph nodes in mesentery, omental masses, ileocaecal masses, suspicious growth in ileum, omental thickening, perforation suspected by tuberculosis. Biopsy was taken from suspicious lesions after laparotomy. Histopathology was shown the granulomatous lesion and diagnosis was confirmed as intestinal tuberculosis.

Statistical analysis was performed by windows bases software Statistical Packages for Social Science (SPSS Version 22.0). The qualitative variables were expressed as frequency and percentage. Comparison of qualitative variables was performed by Chi-square test of Fisher's exact test according to the need basis to see the level of significance. $P$ value less than 0.05 was considered as statistically significant. The type I error was set at $5 \%$ (two-sided) for statistical test.

\section{Results}

A total number of 300 patients under laparotomy were recruited for this study after fulfilling exclusion and inclusion criteria of which 38 (12.7\%) positive cases were found in the study (Table 1).

Majority of the patients were found in age group of 21 to 30 years which was $70(23.3 \%)$ cases followed by the age group of 31 to 40 years and below 20 years which were $62(20.66 \%)$ cases and $56(18.66 \%)$ cases respectively. Mostly affected age group was 21 to 30 years which was 16 (42\%) cases (Table 2).

Among the intestinal tuberculosis positive 38 patients male was predominant than female which was $28(73.7 \%)$ cases and $10(26.3 \%)$ cases respectively (Table 3).

Low socioeconomic people were more affected in positive cases which were 29

Table 1. Intestinal tuberculosis patients in preoperatively unsuspected laparotomy $(\mathrm{n}=$ 300).

\begin{tabular}{ccc}
\hline Intestinal Tuberculosis & Frequency & Percentage \\
\hline Present & 38 & 12.7 \\
Absent & 262 & 87.3 \\
Total & 300 & 100.0 \\
\hline
\end{tabular}

Table 2. Age distributions of among the study population $(n=300)$.

\begin{tabular}{ccccc}
\hline \multirow{2}{*}{ Age Group } & \multicolumn{2}{c}{ Intestinal Tuberculosis } & \multirow{2}{*}{ Total } & P value \\
\cline { 2 - 3 } & Present & Absent & & \\
\hline Less than 20 Years & $8(21.1 \%)$ & $48(18.3 \%)$ & $56(100.0 \%)$ & $70(23.3 \%)$ \\
21 to 30 Years & $16(42.1 \%)$ & $54(20.6 \%)$ & $62(20.7 \%)$ & 0.0085 \\
31 to 40 Years & $8(21.1 \%)$ & $54(20.6 \%)$ & $52(17.3 \%)$ & \\
41 to 50 Years & $6(15.7 \%)$ & $46(17.6 \%)$ & $16(5.3 \%)$ & \\
51 to 60 Years & $0(0.0 \%)$ & $44(16.8 \%)$ & $16(6.1 \%)$ & $300(100.0 \%)$ \\
More than 60 Years & $0(0.0 \%)$ & $262(100.0 \%)$ & \\
\hline
\end{tabular}

${ }^{*}$ Chi-square test corrected by Fisher's exact test was performed to see the level of significance. 
Table 3. Sex distributions of the study population $(n=300)$.

\begin{tabular}{ccccc}
\hline \multirow{2}{*}{ Gender } & \multicolumn{2}{c}{ Intestinal Tuberculosis } & Total & P value \\
\cline { 2 - 3 } & Present & Absent & & \\
\hline Male & $28(73.7 \%)$ & $147(56.1 \%)$ & $175(58.3 \%)$ & \\
Female & $10(26.3 \%)$ & $115(43.9 \%)$ & $125(41.7 \%)$ & 0.0399 \\
Total & $38(100.0 \%)$ & $262(100.0 \%)$ & $300(100.0 \%)$ & \\
\hline
\end{tabular}

${ }^{*}$ Chi-square test was performed to see the level of significance.

Table 4. Socio-economical condition of the study population $(\mathrm{n}=300)$.

\begin{tabular}{ccccc}
\hline \multirow{2}{*}{ SE Condition } & \multicolumn{2}{c}{ Intestinal Tuberculosis } & & Total \\
\cline { 2 - 4 } & Present & Absent & P value \\
High & $0(0.0 \%)$ & $15(5.7 \%)$ & $15(5.0 \%)$ & \\
Middle & $9(23.7 \%)$ & $73(27.9 \%)$ & $82(27.3 \%)$ & 0.238 \\
Low & $29(76.3 \%)$ & $174(66.4 \%)$ & $203(67.7 \%)$ & \\
Total & $38(100.0 \%)$ & $262(100.0 \%)$ & $300(100.0 \%)$ & \\
\hline
\end{tabular}

${ }^{*}$ Chi-square test corrected by Fisher's exact test was performed to see the level of significance.

Table 5. Symptoms presenting in the positive cases $(n=38)$.

\begin{tabular}{ccc}
\hline Symptoms & Frequency & Percentage \\
\hline Acute \& Sub-acute Obstruction & 20 & 52.6 \\
Perforation & 10 & 26.3 \\
Right iliac region mass & 7 & 18.4 \\
Others & 1 & 2.6 \\
Total & 38 & 100.0 \\
\hline
\end{tabular}

(76.32\%) cases followed by middle group which was 9 (23.7\%) cases (Table 4).

Most common presentation in positive cases was acute and sub-acute intestinal obstruction which was found in 20 (52.63\%) cases followed by perforation which was detected in $10(26.31 \%)$ cases (Table 5).

\section{Discussion}

The abdominal TB is a source of significant morbidity and mortality. It is usually diagnosed late due to its nonspecific clinical presentation [6]. Approximately $15 \%$ - $25 \%$ of cases with abdominal TB have concomitant pulmonary tuberculosis [7]. Hence, it is quite important in identifying these lesions with high index of suspicion especially in endemic areas. Among the 300 study population majority of the patients are found in age group of 21 to 30 years which is $70(23.3 \%)$ cases followed by the age group of 31 to 40 years and below 20 years which are 62 (20.66\%) cases and 56 (18.66\%) cases respectively. However, among the intestinal positive 38 cases most common age group is 21 to 30 years which is 16 (42.1\%) cases followed by 31 to 40 years age group and less than 20 years of age group which are $8(21.1 \%)$ cases in each. In 41 to 50 years of age group $6(15.7 \%)$ 
cases are presented with intestinal tuberculosis. The possible cause of affected group is working in the community getting the infection from environment by organism spread by open tubercular cases. In the annual reports of National Tuberculosis Program, Directorate General of Health Service, Dhaka, Bangladesh [6] the statistics is $80 \%$ of the patients are economically productive are age group 15 to 54, which correlate with the study. In this present study male are affected more (73.7\%) and female are less affected (26.3\%). In socio-economic context male are working more than female, for that reason male are more exposed to environment then female and they got infection from open tubercular case. Similar to the present study result Chalya et al. [8] have reported that the age of patients ranged from 16 to 68 years with a median age of 28 with an IQR of 22 to 38 years and the modal age group was 21 to 30 years.

In this study male is predominant than female which is $73.7 \%$ cases and $26.3 \%$ cases respectively. Therefore the present study result indicates that male is most commonly affected by intestinal tuberculosis. Similar to the present study result Chalya et al [8] have reported that $57.8 \%$ are males and $42.2 \%$ are females with a male to female ratio of 1.4: 1 which is consistent with the present study result.

In the study, maximum affected patient are in low socioeconomic condition (76.3\%) which is slightly lower than other studies $6-7$. Similar to the present study result Chalya et al [8] have reported that majority of patients (77.3\%) have come from poor families and this result is consistent with the present study results. The next affected group is middle socioeconomic condition (23.68\%) which is consistent with the other studies [9] [10] [11]. The cause of maximum affected low socio-economic group are in general ignorance and illiteracy; furthermore, other causes are living in the crowded environment as well as in the low ventilated rooms; thus people of low socio-economic condition got infection by inhalation easily [12]. By taking unhygienic food and unboiled milk the patients with low socio-economic condition has got alimentary infection which causes intestinal tuberculosis.

Two types of intestinal tuberculosis produce symptoms differently, ulcerative type produces intestinal perforation, hyperplastic type produces right iliac fossa mass, acute intestinal obstruction sub acute intestinal obstruction. Both types can produce lyrnphadenopathy in these study maximum symptoms presented with acute and sub-acute intestinal obstruction is $52 \%$ to $63 \%$. Right iliac fossa mass is found in $18.4 \%$ and perforation is found in $26.3 \%$ cases; furthermore others presentation is $2.63 \%$ cases. The clinical diagnosis of intestinal tuberculosis is difficult to make due to the nonspecific presentation of symptoms and signs [13]. In addition, it can mimic many diseases and conditions such as malignancy, bacterial infectious disease, and inflammatory disease [14]. Delayed diagnosis or misdiagnosis is directly related to poor outcome in patients who are not able to receive early treatment [15]. The World Health Organization estimates that one-third of the world's population is infected with M. tuberculosis, with the highest prevalence of TB in Southeast Asia [16]. Moreover, the emergence of drug-resistant tuberculosis has become a cause for concern in many 
parts of the world. Therefore proper diagnosis by clinical suspicion is necessary to manage the patients.

\section{Conclusion}

Therefore, high degree of suspicion is needed for the diagnosis and treatment of the intestinal tuberculosis. When a patient presents with abdominal pain and distention, loss of weight, constipation, diarrhoea or alteration of bowel habit, painless lump in the right iliac fossa the physician or surgeon should suspect enteric tuberculosis before any other diagnosis in the context of our country.

\section{Acknowledgements}

We are thankful to the histopathologists who have dedicatedly worked to confirm the diagnosis of the patients.

\section{References}

[1] Mukewar, S., Mukewar, S., Ravi, R., Prasad, A. and Dua, K.S. (2012) Colon Tuberculosis: Endoscopic Features and Prospective Endoscopic Follow-Up after AntiTuberculosis Treatment. Clinical and Translational Gastroenterology, 3, e24. https://doi.org/10.1038/ctg.2012.19

[2] World Health Organization (2009) Global Tuberculosis Control: Epidemiology, Planning, Financing. WHO Report.

[3] Dye, C. (2006) Global Epidemiology of Tuberculosis. The Lancet, 367, 938-940.

[4] Burzynski, J. and Schluger, N.W. (2008) The Epidemiology of Tuberculosis in the United States. Seminars in Respiratory and Critical Care Medicine, 29, 492-498. https://doi.org/10.1055/s-0028-1085701

[5] Alvares, J.F., Devarbhavi, H., Makhija, P., Rao, S. and Kottoor, R. (2005) Clinical, Colonoscopic, and Histological Profile of Colonic Tuberculosis in a Tertiary Hospital. Endoscopy, 37, 351-356. https://doi.org/10.1055/s-2005-861116

[6] Directorate General of Health Services (2003) Tuberculosis in Bangladesh, Annual Report: 2003 National Tuberculosis Control Program. Dhaka.

[7] Akhan, O. and Pringot, J. (2002) Imaging of Abdominal Tuberculosis. European Radiology, 12, 312-323. https://doi.org/10.1007/s003300100994

[8] Chalya, P.L., Mchembe, M.D., Mshana, S.E., Rambau, P.F., Jaka, H. and Mabula, J.B. (2013) Clinicopathological Profile and Surgical Treatment of Abdominal Tuberculosis: A Single Centre Experience in Northwestern Tanzania. BMC Infectious Diseases, 13, 270. https://doi.org/10.1186/1471-2334-13-270

[9] Chau, T.N., Leung, V.K., Wong, S., Law, S.T., Chan, W.H., Luk, I.S., Luk, W.K., Lam, S.H. and Ho, Y.W. (2007) Diagnostic Challenges of Tuberculosis Peritonitis in Patients with and without End-Stage Renal Failure. Clinical Infectious Diseases, 45, e141-e146. https://doi.org/10.1086/523727

[10] Das, H.S., Rathi, P., Sawant, P., Chodankar, C.M., Vyas, K., Patrawala, V. and Dhadphale, S. (2000) Colonic Tuberculosis: Colonoscopic Appearance and ClinicoPathologic Analysis. The Journal of the Association of Physicians of India, 48, 708710.

[11] Steer, D., Essa, A., Clarke, D.L. and Thomson, S.R. (2009) Transverse Colon Tuberculosis Presenting as Colonic Obstruction. South African Journal of Surgery, 47, 31-32. 
[12] Kirsch, R., Pentecost, M., Dem Hall, P., Epstein, D.P., Watermeyer, G. and Friederich, P.W. (2006) Role of Colonoscopic Biopsy in Distinguishing between Crohn's Disease and Intestinal Tuberculosis. Journal of Clinical Pathology, 59, 840-844. https://doi.org/10.1136/jcp.2005.032383

[13] Miah, A.R., Sharma, Y.R., Rahman, M.T., Raihan, A., Roy, P.K. and Hasan, M. (2011) Clinicopathological Profile of Patients with Abdominal Tuberculosis. Journal of Nepal Health Research Council, 9, 169-175.

[14] Hossain, T.M.S. Intestinal Tuberculosis Presenting Profile in Hospital PracticeStudy of 25 Cases.

[15] Choudhury, M.R. (1999) Modern Medical Microbiology. Bishwa Parichaya.

[16] Jehangir, W., Khan, R., Gil, C., Baruiz-Creel, M., Bandel, G., Middleton, J.R. and Sen, P. (2015) Abdominal Tuberculosis: An Immigrant's Disease in the United States. North American Journal of Medical Sciences, 7, 247-252.

https://doi.org/10.4103/1947-2714.157484

\section{Submit or recommend next manuscript to SCIRP and we will provide best} service for you:

Accepting pre-submission inquiries through Email, Facebook, LinkedIn, Twitter, etc. A wide selection of journals (inclusive of 9 subjects, more than 200 journals)

Providing 24-hour high-quality service

User-friendly online submission system

Fair and swift peer-review system

Efficient typesetting and proofreading procedure

Display of the result of downloads and visits, as well as the number of cited articles

Maximum dissemination of your research work

Submit your manuscript at: http://papersubmission.scirp.org/

Or contact jtr@scirp.org 